\title{
Peduncle Rot of Dwarf Wheat caused by Rhizoctonia cerealis
}

D. J . Lovell, Rothamsted Research, Harpenden, Hertfordshire, AL5 2J Q, UK, S. R. Parker, ADAS-High Mowthorpe, Duggleby, North Yorkshire, YO17 8BP, S. Baldwin, IACR-Long Ashton Research Station, Long Ashton, Bristol BS41 9AF, UK and B. A. Fraaije, Rothamsted Research, Harpenden, Hertfordshire, AL5 2J Q, UK

Corresponding author: D. J. Lovell. darren.lovell@bbsrc.ac.uk

Lovell, D. J., Parker, S. R., Baldwin, S., and Fraaije, B. A. 2003. Peduncle rot of dwarf wheat caused by Rhizoctonia cerealis. Online. Plant Health Progress doi: 10.1094/PHP2003-0717-01-HN.

Sharp eyespot, caused by the soil-borne fungus Rhizoctonia cerealis Van der Hoeven (teleomorph: Ceratobasidium cereale D. Murray \& L.L. Burpee), is a common disease of Graminaceae plants including wheat, barley, oats, and rye. The fungus is prevalent throughout the major wheat growing regions of the world and is sometimes associated with pre- and post-emergence damping off and shoot death of seedlings. However, the symptoms most frequently observed are lesions occurring on stem bases generally restricted to tissue below the second node, having been observed up to a height of $35 \mathrm{~cm}$. Estimates of yield losses due to this disease are generally low $(1,2)$. Therefore, improved resistance has not been a priority in plant breeding.

Lesions, similar in appearance to those caused by R. cerealis, were observed in the field in late May on the flag leaf sheaths (Fig. 1) of dwarf winter wheat isogenic lines, Mercia Rht3 and Mercia Rht10, sited at Long Ashton, England, but not on the non-dwarf isogenic Mercia rht line growing in the same field. Within two weeks, the pathogen had penetrated to the underlying peduncle tissue (Fig. 2). In severe cases, "rotting" of the peduncle, and production of mycelium on the internal surface of the flag leaf sheath occurred (Fig. 3). Peduncle rot caused premature spike senescence (white heads) and reduced grain production severely. On some tillers, mycelium was present on the lower florets of the spike, however no lesions were observed on these tissues. Isolates of fungal mycelium were taken from infected tissues and plated on PDA. Fungal morphology and growth rate conformed to the original description of $\mathrm{R}$. cerealis.

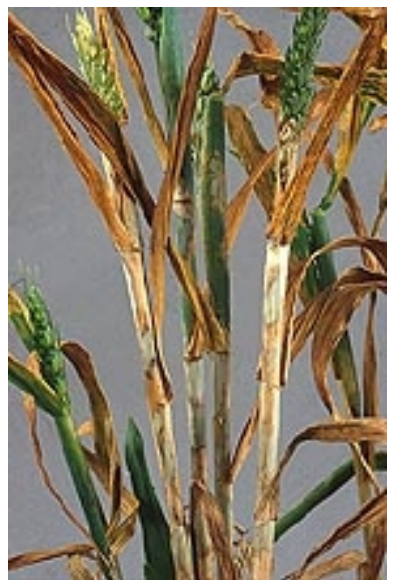

Fig. 1. Sharp eyespot symptoms on flag leaf sheath of dwarf winter wheat.

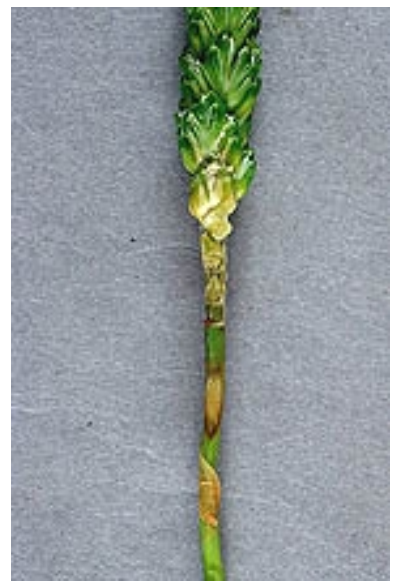

Fig. 2. Sharp eyespot symptoms on peduncle of dwarf winter wheat. 


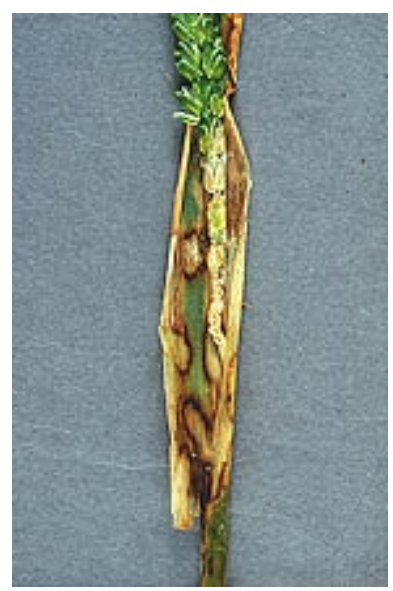

Fig. 3. "Peduncle rot"

resulting from penetration of sharp eyespot.

To further confirm the causal pathogen, DNA was extracted directly from visibly infected flag leaf sheaths, mycelium on the peduncle, and symptomless flag leaves. The primer set Rc2F/ R (3) was used to establish presence of R. cerealis. The primer set amplified a 800 bp product from the leaf sheath sample and the isolated mycelium, indicating the presence of $\mathrm{R}$. cerealis, but no product was amplified for the flag leaf DNA (Fig. 4). To satisfy Koch's postulate, samples of leaf sheath and peduncle tissue from the two dwarf winter wheat cultivars, obtained from the field, were sectioned into 2 -cm portions and surface sterilised and then plated onto both tap water agar and potato dextrose agar (Oxoid). Resulting isolates were used to inoculate glasshouse-grown plants of cultivar Mercia rht and the non-dwarf spring wheat cultivar Axona (at approximate GS 51) on both stem base and flag leaf sheath tissues. Inoculations were done by taking 5-mm agar discs from two-week-old isolates and applying them to the plant tissue surface using parafilm. Plants were maintained in a heated glasshouse (mean temperature approximately $16^{\circ} \mathrm{C}$ ). Discs were removed after 5 days and plants observed regularly for development of symptoms.

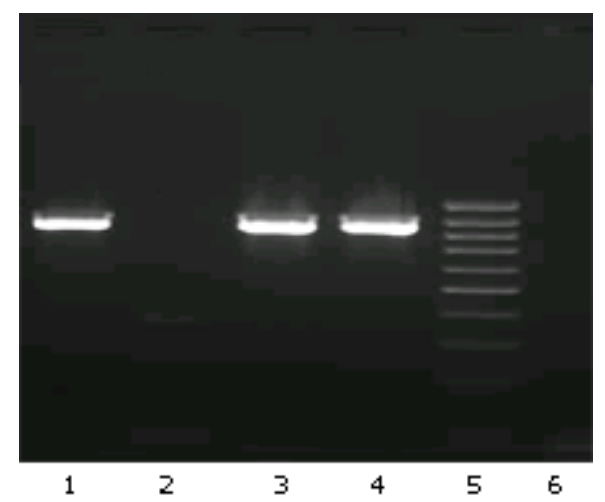

Fig. 4. Identification of Rhizoctonia cerealis by PCR using the primer set Rc2F/R. PCR samples $(15 \mu \mathrm{l})$ were analyzed in agarose gel electrophoresis. Lane 1, visibly infected sheath of flag leaf; Lane 2, symptomless flag leaf; Lane 3, isolated mycelium from peduncle tissue; Lane $4, R$. cerealis pure culture grown in vitro; Lane 5, 100-bp DNA size markers; Lane 6, distilled water.

Typical symptoms of sharp eyespot infections were observed, at site of infection, on both cultivars at 7 to 10 days post inoculation. Furthermore, at 12 to 15 days post inoculation, symptoms of early "peduncle rot" were observed on plants where inoculation of the flag leaf sheath had resulted in infection. These symptoms became severe, causing white heads, approximately 20 days post inoculation. Mycelium was isolated from the leading edge of developing peduncle lesions and plated on agar as previously described. Identification of 
colony morphology and hyphal branching was consistent with that of the applied fungal material.

The dwarf wheat used in this study had a height, at maturity, of 35 to $50 \mathrm{~cm}$ compared to the conventional cv. Mercia germplasm with a height of 90 to 100 $\mathrm{cm}$. R. cerealis lesions on the flag leaf sheath and peduncle tissues of dwarf wheat occurred in field crops at a height of between 25 to $30 \mathrm{~cm}$ above the ground, within the reported height range to which it has been observed on the stem tissues of many cereal crops. Natural infections of the non-dwarf lines were not observed on these tissues, being confined to the stem bases (below first and second nodes) only. However, when these tissues were artificially inoculated in the glasshouse, symptoms were observed as in the isogenic dwarf lines. Therefore, it is likely that infection of the peduncle tissue was a result of the reduced height of the crop rather than a physiological change in host tissue or susceptibility.

Sharp eyespot is assumed to be of little economic importance in the UK (1), and no specific recommendations are made for its control. Whilst both dwarf and non-dwarf lines had a high incidence on infection in the field, white heads were only evident on plants where infection of peduncles was observed. Confinement of white heads to infected plants with lesions on peduncle tissue suggests that damage to this tissue is likely to have a greater affect on plant health and grain formation than on plants where lesions are confined to the base of stems.

There has been a general trend to reduce crop height over the past 30 years. Typically, commercial cultivars now have a height of 65 to $80 \mathrm{~cm}$, with the flag leaf sheath being some $20 \mathrm{~cm}$ below that. The observations of peduncle rot in this study suggest that the continued trends of reduction in plant height through breeding or crop husbandry (e.g., application of plant growth regulators), would increase the impact of $\mathrm{R}$. cerealis on wheat production in temperate regions.

\section{Acknowledgements}

Thanks to Tom Hunter for help with and advice on identification and isolation of the fungus. Isogenic lines were kindly supplied by J ohn Innes Centre, Norwich, UK. This work was funded by the UK Department of Environment, Food and Rural Affairs and by the Home Grown Cereals Authority, UK.

Literature Cited

1. Clarkson, J. D. S., and Cook, R. J. 1983. Effects of sharp eyespot on yield loss in winter wheat. Plant Pathol. 32:421-428.

2. Cromey, M. G., Butler, R. C., Boddington, H. J ., and Moorhead, A. R. 2002. Effects of sharp eyespot on yield of wheat (Triticum aestivum) in New Zealand. N. Z. J . Crop Hort. Sci. 30:9-17.

3. Nicholson, P., and Parry, D. W. 1996. Development and use of a PCR assay to detect Rhizoctonia cerealis, the cause of sharp eyespot in wheat. Plant Pathol. 45:872883. 